\title{
PSICODINÂMICA DO TRABALHO DOS MÚSICOS DE UMA BANDA DE BLUES
}

\author{
Daniela Tavares Ferreira de Assis \\ Kátia B. Macedo \\ Universidade Católica de Goiás, Goiânia, Brasil
}

\begin{abstract}
RESUMO: O presente artigo apresenta dados de uma pesquisa que levantou as vivências de prazer e sofrimento de cinco componentes de uma banda de blues, e o trabalho como construtor de identidade por meio do discurso de profissionais: uma banda de blues com renome no mercado fonográfico da região Centro-Oeste do Brasil. O delineamento deste estudo privilegiou os preceitos "dejourianos" como perspectiva norteadora de prazer e sofrimento. Os dados coletados através de entrevistas foram tratados por meio da Análise Gráfica do Discurso de Lane (1985). Como resultados, emergiram categorias relacionadas à percepção que tinham sobre: as condições de trabalho, as relações de trabalho, organização de trabalho, as vivências de prazer e sofrimento no trabalho e as estratégias de enfrentamento. Como indicadores de prazer e sofrimento, foram citados: a dupla jornada de trabalho, o sentido do trabalho de criação vinculado á arte e o preconceito social que enfrentam pelo fato de ser artista e trabalhar à noite.
\end{abstract}

PALAVRAS-CHAVE: Psicodinâmica do trabalho; música; banda e organização.

\section{THE PSYCHODYNAMICS OF WORK OF MUSICIANS OF A BLUES BAND}

ABSTRACT: This article presents the results of a research that was carried out with blues band musicians in the center-west region of Brazil. It seeks to learn about the suffering and pleasure experiences of the five components of this blues band, which is famous in the region. The delineation of this study had privileged the concepts developed by Dejours as a guideline, focusing on the pleasure and suffering experiences. Data had been collected by interview and had been treated by Lane's Graphic Analysis of Speech. The results indicate pleasure and suffering experiences as: double work journey, sense of work as a creative one and related to art, and social prejudice for being artists and working at night. Categories related to the musicians' perceptions had also emerged involving work conditions, work relations, organization, pleasure and suffering experiences and strategies of confrontation.

KEYWORDS: Psychodynamics of work; music; band and organization.

O trabalho, como um processo histórico e social, é determinado pelos modos de produção da sociedade. Os trabalhadores da arte se constituem em objeto de estudo claramente situado no espaço de interface dos fenômenos psíquicos e sociais, evidenciando-se que tal interface pode ser estudada a partir de várias dimensões.

Para Enriquez (2006), quando uma pessoa se reconhece como sujeito psíquico é para aprender a se defender da fantasia da dominação total e se perceber como sendo um indivíduo clivado, submetido à perda, à falta, ao trabalho de luto e ao sofrimento, com dívidas a pagar para poder realizar, pelo menos em parte, o princípio do prazer. O sujeito psíquico é, assim, um ser que reconhece as suas contradições e os seus conflitos, sabendo que não é totalmente senhor de seus próprios desejos pelo fato de existir o inconsciente.
No mundo do capital globalizado, os antigos valores foram redimensionados, e os aspectos econômicos se intensificam a cada dia, causando conseqüências ao nível coletivo: enfraquecimento de vínculos sócias; competição exacerbada; utilização inadequada dos recursos naturais; enfraquecimento dos movimentos sociais; diminuição das lutas sindicais e, a exacerbação da , "impotência" dos trabalhadores em fazer frente a uma lógica do capital.

Segundo Polato (2004) o trabalho: “... é a dimensão ontológica do ser social, pois é através dele que o homem realiza sua intenção na natureza. Essa intenção é identificada no processo ao mesmo tempo em que a realidade é transformada" (p. 48).

O trabalho, como construtor de identidade e inclusão social, atua sobre o sujeito, interferindo na sua vida 
como um todo, inclusive na relação saúde-doença. Como todo trabalho, necessita de investimento afetivo para que possa ser realizado. Neste sentido, Codo, Menezes, Tavares, Lima e Diniz (2004) afirmam que o trabalhador constrói sua identidade na sua relação diária com a própria vida, estabelecendo uma tríplice relação entre identidade-trabalho-relações sociais e afetivas.

Bendassolli (2003-2004) afirma que a associação entre trabalho e identidade vem se tornando problemática, e que seus sentidos foram variando ao longo do tempo, bem como a associação em relação ao sentido da existência. Durante boa parte dos dois últimos séculos, o relacionamento entre o sentido que uma pessoa atribuía a si mesma, sua identidade e o trabalho remunerado que ela desempenhava durante a vida, era fonte de relativa estabilidade e segurança. Trabalho e identidade eram como duas realidades intrinsecamente relacionadas. Contudo, nas últimas décadas, tornou-se comum a crença de que aquele modelo chegou ao seu fim. De acordo com essa perspectiva, o trabalho teria perdido sua centralidade no processo de constituição da identidade.

O trabalho "pode ser" um fator de inclusão social e possibilidade de autonomia. Por isso, o trabalho na arte, ou seja, o trabalho de artistas adquire um fator essencial para enfrentar a alienação e exploração de capital.

A discussão sobre o que vem a ser arte ocupa os homens desde a Antigüidade. As formas de suas manifestações, os pontos de vista acerca do assunto e seu conceito foram se modificando ao longo da história da humanidade.

A arte, neste sentido, consolida-se como intercâmbio entre sujeito e objeto, exigindo o diálogo do sujeito com o seu outro, processo pelo qual é possível simbolizar o mundo. Não se trata, entretanto, numa concepção 'adorniana', de identidade entre ambos, mas de desestabilizar os princípios pelos quais a verdade só se revelaria na proeminência de um ou de outro (Fabiano, 2003).

Se o artista não é mais dotado de inspiração sobrenatural, e a obra de arte passa a ser vista como trabalho, arte e técnica se apresentam como sendo inseparáveis. Assim, é preciso possuir habilidades específicas, manuais e racionais, para produzir uma obra de arte (pintura, escultura, música, poesias, etc.). Para Freitas (2005), na arte, o estilo nunca foi seguido à risca pelos grandes artistas, que viam nele uma forma de expressar ao sofrimento que surdamente ocorria no caos das contradições da vida capitalista. Essa eloquiência do estilo significaria mediar os antagonismos sociais historicamente sedimentados na vivência individual através da força da síntese dos elementos dispersos na obra de arte, na medida em que tal unidade não seria simplesmente imposta, mas surgiria a partir deles.

A obra de arte seria o "fruto amadurecido" que se desprenderia do artista, e que será dado a conhecer, como um ser único e autônomo, a posteriori, com o seu "desprendimento". A obra de arte é, nesse sentido, um risco, já que não haveria como prevê-la; e até mesmo o artista só a conheceria plenamente quando ela estivesse pronta, Johanson (2004).

Todo o jogo da criação é interno, e se realiza dentro de um campo de hesitação. Para Johanson (2004) a hesitação não é senão esse risco de se lançar num movimento que não tem mais razão de seguir nesta ou naquela direção, mas que só será reencontrado depois de realizado. A liberdade é o alcance desse esforço de mudança sem garantias. $\mathrm{O}$ ato livre,, tal como a obra de arte, é o "fruto amadurecido" que poderia não amadurecer. A criação se dá a partir dessa determinação interna, que atravessa a hesitação e faz com que obra, no caso do artista, e nossos próprios atos, com relação a nós mesmos, nasçam. Enfim, o artista toma conhecimento de sua experiência por intermédio de sua obra, e até mesmo para ele, essa experiência não será de todo revelada.

Para os artistas, o tempo para lazer é escasso, pois nos momento de desfrutarem de fruição deste período "livre", eles proporcionam prazer para as pessoas. As atividades artísticas exigem tempo e investimento (emocional e financeiro), talvez seja exatamente na indústria cultural que a arte tenha perdido a sua característica essencial, passando a ser vista como restrita a quem pode pagar.

O aumento deste campo de estudos (Alves, 2006; Amaral, 2006; Mascarenhas, 2005, 2006; Padilha, 2006; Pellegrin, 2006), nas últimas décadas, se deu em decorrência alguns fatores. $O$ primeiro está ligado à ampliação do público, do mercado de bens simbólicos e da importância do setor de serviços na sociedade, que o transformou em alvo privilegiado dos pesquisadores. Este crescimento da área levou a uma revisão das políticas públicas e privadas para a cultura e as artes. Os novos desafios derivados das mudanças, que abarcam desde a ampliação e a segmentação do público, até a redefinição das fronteiras tradicionais - que haviam configurado este universo - geraram uma série de pesquisas acadêmicas (Dimatos, 1999; Graciolli, 2006; A. B. F. Macêdo, 2003; Maheirie, 2001; Polato, 2004), formuladas a partir de demandas específicas do setor, que se transformaram em base de informação para as estratégias de atuação nesse campo.

As atividades de lazer estão ligadas ao consumo, seja ele concreto ou não, e o consumo se configura também no mundo das artes cênicas, culturais e musicais.

Dentre as atividades relacionadas à arte, música e criação, nota-se a presença de conteúdos artísticos desde quem cria as letras (ritmos e melodias), o compositor, até os que a interpretam, músicos, e ainda os que trabalham com eles nos bastidores. Estes trabalhadores têm rotinas bastante diferentes com relação aos horários de trabalho, alimentação e vida social. 


\section{A música e os músicos}

No senso comum, o estereótipo vigente é de que os músicos possuem uma imagem vinculada ao uso de drogas e álcool, sendo muitas vezes marginalizados pela sociedade, além da idéia de que a arte não é trabalho, o que pode ser denotado na expressão "leva a vida na flauta".

Enriquez (2001) comenta que as pessoas podem ser excluídas socialmente quando não são obcecadas pelo sucesso, pelo jogo de aparências, e por não gostarem do efêmero ou de atitudes alienadas. Ao adotarem uma postura que critica atitudes de consumo estimuladas pela mídia, resistem à adesão maciça e alienada de parte da indústria cultural.

Ao produzir a música, os músicos articulam os sons e o silêncio numa estrutura temporal própria e única. Preocupado em definir este tipo de atividade, Araújo (1998) observou que, para começar, o conceito de tempo, amparado numa visão evolucionista, precisa ser superado. Para a autora, é necessário considerar o tempo qualitativo, quando a referência é a música. O tempo qualitativo seria aquele no qual a consciência é capaz de, concomitantemente, interpermear o presente, passado e projeções futuras.

Maheirie (2003), afirmou que a música é uma linguagem reflexivo-afetiva, capaz de construir sentidos coletivos e singulares, e que o processo de criação musical deve ser compreendido sempre como um produto histórico e social. Assim, a música pode ser vista como uma prática determinada, situada num contexto específico, mas sempre relacionando seu tempo a expressões passadas, presentes e futuras.

O perfil dos músicos, segundo Tamayo, Faria e B. Filho (1998), é caracterizado pela busca por mudanças, sensações novas e prazer, sendo indicado por uma prevalência dos valores relacionados ao individualismo, da autonomia intelectual e afetiva e abertura à mudança. Os músicos apresentam motivações diferentes, de outros trabalhadores, pois lidam com a criação de novas partituras, atividades que exigem inovação, fruição, criatividade, novas sensações de prazer e uma boa dose de estimulação.

Deve-se ressaltar que há os músicos compositores e os que interpretam as composições. No presente trabalho, escolhemos pesquisar músicos que compõem pelo fato de sua composição possibilitar autonomia, criatividade e identidade.

O Blues é um gênero musical maior, que, inicialmente, exerceu grande influência na música popular "norte-americana" e, posteriormente, em toda a música pop mundial. Inicialmente, parte fundamental da música negra tradicional, abrange diversos subgêneros, que podem ser localizados histórica e geograficamente. A. B. F. Macêdo (2003) afirmou que o blues nasceu com o pri- meiro escravo na América. Da África, os negros levaram sua expressão vocal básica, os hollers (gritos). Os gritos eram como uma forma de comunicação nos campos do Sul dos Estados Unidos, e muitas canções evoluíram a partir deles. Eram também ouvidos nas ruas das cidades, onde vendedores ambulantes anunciavam seus produtos ou serviços através de um pungente canto rítmico, onde os negros anunciavam a chegada e a partida dos trens nas estações. Esta marca individual se projetou também no blues.

A palavra blues possui uma concepção de tristeza, sofrimento, melancolia, pois desde seu início, serviu como forma de expressão artística desses temas.

No Brasil, e especificamente em Goiás, os músicos já se deparam com dificuldades para sobreviver a partir de sua música, principalmente se o estilo for o Blues, privilegiado da banda escolhida, o que já indica uma certa atitude crítica, pois tocar na terra da música sertaneja é, no mínimo, um ato de crítica e coragem.

Para estes profissionais, nem tudo são flores como se imagina, nem sempre existe o sucesso e o glamour esperado. Dentre as dificuldades financeiras, sociais, afetivas e econômicas, há uma sobrecarga de trabalho, sendo que o músico tem outro trabalho formal para garantir sua sobrevivência, e para fazer sua arte, deve se desdobrar para uma dupla jornada de trabalho, ou seja, "o feijão e o sonho".

Dentro das abordagens psicológicas, optou-se pela psicodinâmica do trabalho pelo fato dela possibilitar a captação da subjetividade no trabalho

\section{A abordagem psicodinâmica do trabalho}

Psicodinâmica do Trabalho advém de um movimento, na década de 1950, que visava realizar pesquisas para explicar os transtornos mentais dos trabalhadores produzidos por modelos de gestão baseados no taylorismo, buscando promover melhorias no mesmo, de acordo com Ferreira e Mendes (2003).

Psicodinâmica é um termo proveniente da teoria psicanalítica, e designa o estudo dos movimentos psicoafetivos gerados pela evolução dos conflitos inter e intra-subjetivos. Assim, ela se opõe à metapsicologia, que estuda os processos, as estruturas e os equilíbrios das forças na esfera abstrata dos mecanismos, das instâncias ou tópicos do aparelho psíquico e da economia das pulsões. Para Dejours:

... a psicodinâmica do trabalho abre caminho para perspectivas mais amplas, que, como vemos, não abordam apenas o sofrimento, mas ainda, o prazer no trabalho: não mais somente o homem, mas o trabalho nos detalhes de sua dinâmica interna. A psicodinâmica não pode mais ser considerada como uma entre tantas outras especialidades. (2004, p. 53). 
A psicodinâmica do trabalho tem por objeto os processos intersubjetivos que tornam possível a gestão social das interpretações do trabalho pelos indivíduos. Segundo Dejours (2004), o essencial dos problemas submetidos à análise psicodinâmica das situações de trabalho provém do desconhecimento e mesmo da inépcia quanto às dificuldades concretas com as quais os trabalhadores são confrontados pelo fato da imperfeição irredutível da organização do trabalho, e recorre à técnica da interpretação.

A análise da psicodinâmica sugere que a retribuição esperada pelo indivíduo seja fundamentalmente de natureza simbólica, ou seja, reconhecimento da realidade que representa a contribuição individual, no sentido de gratidão. A construção do sentido do trabalho pode transformar o sofrimento em prazer. Esta dinâmica do reconhecimento constitui a realização pessoal no campo social que ganha um lugar junto à construção da identidade.

Na obras da psicodinâmica do trabalho de Dejours $(1992,1994,2004)$, resultaram algumas categorias com vários elementos que influenciam os indicadores do sofrimento ligado ao trabalho, tais como: organizações de trabalho, condições de trabalho, relações de trabalho, prazer e sofrimento, e estratégias de enfrentamento.

Cada categoria se caracteriza por núcleos de pensamento que podem ser resumidos da seguinte forma:

1. Organização de trabalho - Para Lacaz (2000), a organização nos locais de trabalho deveria ser elemento norteador das relações de trabalho, em vista da introdução de novas tecnologias e da automação cada vez mais intensa que se observa nos setores produtivos mais modernos. Para este autor, é inadmissível falar em qualidade do produto sem tocar na qualidade do ambiente e condições de trabalho, o que seria sobremaneira auxiliado pela democratização das relações sociais do trabalho.

Além do desgaste do exercício do prazer no trabalho, entra-se no domínio sofrimento, quer dizer, do sofrimento patogênico. Este surge assim que a relação do homem com a organização do trabalho é permanentemente bloqueada. Quando a tensão atinge seu apogeu, nada mais interfere a favor do reconhecimento do sofrimento entre os profissionais, nem dos vínculos entre este sofrimento e os impasses da organização do trabalho.

2. Condições de trabalho - Um ambiente de trabalho é condição necessária para um bom desenvolvimento profissional. Poderia ser também o lugar do hobby, do lúdico, do poético, da convivência harmoniosa entre níveis hierárquicos democraticamente embaralhados, cuja pretensa proximidade dilui as diferenças e os conflitos “... são as condições de trabalho que são acusadas: os vapores, as pressões, as temperaturas, os gases tóxicos, o ruído... em resumo: as condições físicas e químicas de trabalho" (Dejours, 1992, p. 66). As pressões psíquicas, mecânicas, quí- micas, físicas e biológicas do local de trabalho (onde o único alvo é o trabalhador) levam às vivências de sofrimento e consequentemente às estratégias defensivas (coletivas).

Para Dejours (1992), mesmo as más condições de trabalho são, no conjunto, menos temíveis do que uma organização de trabalho rígida e imutável, pois esta situação não permite que o trabalhador faça uma adaptação do trabalho ao seu estilo de personalidade e nem ao seu estilo físico. Heloani e Capitão (2003) constataram que a qualidade de vida do trabalhador, especialmente os que vivem no terceiro mundo, vêm-se degradando dia após dia. Doenças até então inexistentes ou restritas a certos nichos empresariais tornaram-se restritas a todos, parece até que o encolhimento do mercado de trabalho, as lutas dos trabalhadores restringem-se apenas às sobrevivências, não importando o preço a ser pago.

3. Relações de trabalho - A relação com o trabalho ou com os outros trabalhadores tende a se tornar a principal referência das pessoas, o sentimento de identidade social é fortemente ancorado na relação profissional.

Para Pagés (1982), o conflito intragrupo parece ser em muitos casos apenas um mecanismo de defesa, que protege os participantes. O conflito exerce para o grupo a mesma função de defesa que os sintomas para o neurótico. Este autor considera a qualidade das relações que ela propicia, pois somente a partir desse processo reflexivo sobre o próprio trabalho, que essa reapropriação vai permitir aos trabalhadores a mobilização para impulsionar as mudanças necessárias para tornar este trabalho mais saudável.

4. Vivências de prazer e sofrimento - Segundo Ferreira e Barros (2003), as vivências de prazer-sofrimento têm sido consideradas pela Psicodinâmica do Trabalho como um construto dialético, podendo haver a preponderância de uma sobre a outra.

Para Brant e Minayo-Gomez (2004) o sofrimento como uma dimensão intolerável nas organizações pactua com a linguagem que, além de representar, tem a função de criar laços discursivos entre os sujeitos, as coisas ao redor, de modo a estruturar um universo de sentido. Estes autores apontam ainda que o sofrimento têm intensidades diferentes para os trabalhadores de uma mesma organização. $\mathrm{O}$ que o sofrimento é para um, não é necessariamente para outro, mesmo quando submetidos às mesmas condições ambientais adversas.

As vivências de prazer são provenientes da satisfação dos desejos e necessidades do corpo-mente, algumas características do prazer são: as relações com as pessoas, relações sociais de trabalho de produção de bens e serviços, avaliação consciente de que algo vai bem, gratificação do reconhecimento, da valorização no trabalho, 
identidade e expressão da subjetividade individual, e a vivência da sublimação que permite a descarga do investimento pulsional (Ferreira \& Mendes, 2001). Outras fontes de prazer são citadas por Pagés (1987), como: salário, carreira, viagens, contatos e o prazer de identificarse com o poder da organização.

Se há prazer no trabalho - relevando também ele da racionalidade prática - este prazer só pode advir do ganho obtido no trabalho justamente no registro da construção da identidade e da realização de si mesmo, “... o prazer do trabalhador resulta da descarga de energia psíquica que a tarefa autoriza, o que corresponde a uma diminuição da carga psíquica do trabalho" (Dejours, 1994, p. 59).

Nesta direção, o prazer-sofrimento é um construto único, originado das mediações utilizadas pelos trabalhadores para manter a saúde, evitando o sofrimento e buscando alternativas para obter prazer, (Ferreira \& Mendes, 2001).

5. Estratégias de enfrentamento - Para Dejours (2004), Ferreira e Mendes (2001) o homem que está engajado em estratégias defensivas para lutar contra o sofrimento no trabalho não abandona seu funcionamento psíquico, ao contrário, leva suas contrariedades mentais consigo e necessita da cooperação em seu círculo de relações mais íntimas para manter suas defesas mentais contra o sofrimento. Assim sendo, as estratégias operatórias e de mobilização coletiva são mais apropriadas do que a defensiva para manter os trabalhadores próximos da saúde, principalmente quando ocorre compartilhamento da estratégia operatória, “... se falta reconhecimento, os indivíduos engajam-se em estratégias defensivas para evitar a doença mental, com sérias consequiências para a organização do trabalho...” (Dejours, 2004, p. 77).

\section{Delineamento metodológico do estudo}

Sob a perspectiva da psicodinâmica do trabalho, a metodologia utilizada foi baseada nas obras de Dejours (1992, 1994, 1999, 2004); Lancman e Heloani (2004) e Mendes (2002). Sendo “do ponto de vista teórico, o dispositivo metodológico da psicodinâmica do trabalho age como uma lente de aumento que torna visível e eventualmente volta a dinamizar a gestão da organização" (Dejours, 2004, p. 93-94). A metodologia qualitativa é um método que privilegia o discurso como fonte de acesso à subjetividade dos participantes. Optou-se pelo estudo de caso pela sua possibilidade de aprofundamento nas interações do grupo pesquisado.

\section{Participantes}

Todos os músicos componentes da banda participaram da pesquisa. $\mathrm{O}$ motivo se deve à possibilidade de melhor compreensão da estrutura dinâmica da banda.
Sua primeira formação foi em 1985, e, em 2007, a banda era formada por três músicos e dois assistentes que prestavam serviços técnicos. A banda já gravou sete Cd's (composições próprias), já se apresentou em quase todo o Brasil e em conhecido evento latino de música.

Os componentes atuam, em sua maioria, em atividades paralelas, em turnos diversificados durante a semana, e, com isso, ficavam privados de tempo livre para o lazer e do convívio familiar aos finais de semana. Todas estas características foram analisadas, ainda por se tratar de uma banda onde o trabalho é capaz de desencadear vivências de prazer e sofrimento.

A banda em estudo foi denominada XYZ, sigla fictícia, com o objetivo de preservar seu anonimato. Para preservar a identidade dos participantes, foram apresentados com nomes fictícios e os dados sócio-demográficos foram coletados no período entre maio a junho de 2006.

\section{Instrumentos}

Utilizou-se para a coleta de dados a entrevista semiestruturada, além de observações durante alguns ensaios. A construção do roteiro para as referidas entrevistas considerou as categorias: do histórico da banda; das condições de trabalho; das relações de trabalho; de horário de trabalho; de prazer e sofrimento e organizações de trabalho. Incluindo a conclusão, o roteiro continha quarenta e duas perguntas.

A entrevista semi-estruturada permitiu uma orientação aos tópicos principais de investigação, e possibilitou o surgimento de novos questionamentos em seu decorrer. Os dados foram registrados por meio de gravação e transcrição na íntegra.

\section{Procedimentos}

O Nosso primeiro contato com a banda aconteceu em novembro de 2005, com o objetivo de fazer o convite para a participação na pesquisa. De imediato o músico (cantor e compositor) A. autorizou e informou aos outros componentes, demonstrando interesse no trabalho. Posteriormente foi feito o convite aos outros e, após a autorização por escrito, iniciou-se a coleta de dados: as entrevistas semi-estruturadas.

A realização das entrevistas foi realizada em horários pré-acordados de forma que não prejudicasse a rotina de apresentações e ensaios. Foi explicado o objetivo da pesquisa, forma de registro dos dados, ou seja, a gravação em fitas cassetes, e também foi dada a garantia do sigilo das informações obtidas, preservando-se o anonimato.

A técnica da análise de dados utilizada foi a Análise do Discurso de Lane (1985). Para Lane, a comunicação com os outros é a experiência adquirida pela ação, medi- 
ados pela linguagem, pois permite libertar as emoções, pensamentos e ações. Segundo Cabral (1999), o foco da Análise do Discurso é a forma como a língua é produzida e interpretada em um dado contexto. Por sua amplitude, ela pode ser trabalhada como um instrumento de pesquisa em uma variedade de áreas, não excluindo a incorporação de outras metodologias.

A técnica tem como proposta: analisar e procurar graficamente os núcleos do pensamento, através das palavras que se repetem (ou dos sinônimos), mas seguindo a continuidade do discurso, utilizando a sequência dos números para cada unidade de significado, sujeito ou predicado. Ela permite levantar os núcleos e categorias que emergem do discurso e indicar a composição do pensamento e a formação das representações acerca do assunto abordado.

Segundo K. B. Macêdo (2001), o procedimento da análise gráfica do discurso permite tratar os dados discursivos e levantar os núcleos de pensamento emergentes e as categorias compostas por eles, de forma a se obter as representantes presentes na elaboração do discurso, permitindo assim a compreensão do que o autor do discurso pensa ou representa sobre determinado assunto. Quando os núcleos de pensamento possuem interfaces, eles constituem categorias, e, ao se representar graficamente o discurso, utilizando os núcleos e categorias, o pesquisador consegue visualizar a sequiência do pensamento e a interação das categorias e núcleos.

\section{Resultados}

Os resultados serão apresentados considerando as categorias:

\section{Condições de Trabalho}

Bem, o estúdio é nosso... é maravilhoso com relação aos outros... tem parede dupla acústica, ar condicionado, a medida é exatamente a melhor, então daquele padrão mas pra não virar uma farmácia onde fica tudo de qualquer jeito sabe? Então quando a gente vai tocar nos shows é bem legal, me sinto bem satisfeito.

Com certeza já aconteceu vários [acidentes], com relação a choque elétrico, éé queda de palco bastante alto, éé tombo de caixa de som de cima de braço de cima de pé... éé . . às vezes se cortar, eu trabalho com algumas ferramentas cortantes esse tipo de coisa acontece com bastante frequiência, eu tento ser bastante cuidadoso com relação principalmente choque é um caso mais sério, mas às vezes num dá pra prevenir . . . e aí num dá certo, mas eu tento ser bastante cuidadoso.

Relações de trabalho/organização de trabalho

"Muito prazer... muito bem quando to trabalhando na banda, sinto satisfação, já fui bancário, auxiliar de escritório, já vendi até melancia na feira, mas o que mais gosto é música."

"Orgulho, principalmente porque... nesse... no caso específico dessa banda é muito digno o trabalho, muito respeitoso, então... realmente eu sinto orgulho porque vale a pena trabalhar."

"Prazer, prazer no que, no que eu tô fazendo... porque... acho que é o principal né? Porque acho que se não tiver esse prazer, acho que não precisa né? Tocar, sair pra tocar, e... se desdobrar... como a gente se desdobra né?"

\section{Vivências de Prazer no Trabalho}

É meu trabalho é tudo pra mim mais até que qualquer outra coisa, eu gosto bastante da minha família, gosto dos meus relacionamentos pessoais com amigos, parentes, éé relacionamentos amorosos, mas o meu trabalho é a minha paixão então na minha vida ele é tudo que eu realmente eu faço o que eu gosto.

"Pra mim é um sonho viver de música, significa uma vitória, não vivo só da banda, tenho apoio da família, sempre tive, pra mim é uma conquista. Me sinto realizado."

\section{Vivências de sofrimento no trabalho}

"Única dificuldade é de não ter em casa um estúdio, poderia estar tocando em casa, sabe? Mas os instrumentos ficam todos lá... e aqui eu num tenho espaço."

Todas essas que já eu te falei né? Problemas tipo por fora, as pessoas não te reconhecerem, não te dar condição de trabalhar, é... é... morar em Goiânia, ta, vou largar Goiânia,eu vou mudar pra São Paulo então vou tocar lá que é muito mais fácil, vou mudar pra Campinas que as coisas estão acontecendo tudo lá, só que a minha vida profissional que me dá dinheiro, que me da sustento, é em Goiânia, então eu vivo a situação paradoxal, se por um lado o que me sustenta está em Goiânia, o que me viabilizaria um sucesso maior do ponto de vista da banda não esta aqui entendeu? . . .

\section{Estratégias de enfrentamento no trabalho}

... hoje em dia eu dou piti, mas às vezes controladamente né?Por que quando eu dou piti, depois você vai perguntar pros outros desse tecladista que tava com a gente, ele dá piti gigantesco, homérico, coisa que eu nunca iria falar ele quase mooooorre entendeu? . . .

. . a após alguns anos eu já fiquei bastante chateado com muita coisa. Porque o meio ainda é muito ama- 
dor então eu... ainda não consegui me controlar quase que numa totalidade que ter calma pra conversar e com todo mundo, Às vezes eu estouro, grito, brigo pra poder trabalhar de uma forma legal ,ter conforto, ter higiene, ter qualidade, então eu às vezes fico bastante chateado e me controlo, mas às vezes fico bastante chateado ...

\section{Análise e discussão dos resultados}

Os indicadores de prazer e sofrimento nos trabalhadores se dá a partir das cinco categorias relacionadas à psicodinâmica do trabalho, independente do nível hierárquico. Considerando a teoria 'dejouriana' utilizada, os participantes que proporcionam lazer têm uma dupla jornada de trabalho, pouco reconhecimento social e financeiro, atuam à noite e sujeitos a apresentarem sintomas gravíssimos relacionados à saúde física e mental.

A organização do trabalho é vista como uma relação socialmente construída e não somente em sua dimensão tecnológica, e configura a divisão de tarefas e o modo como as mesmas serão executadas, às vezes informalmente.

Se de um lado, o profissional que pensa nas suas relações de trabalho e atribui um sentido às situações, mas depende das condições sócio-econômicas oferecidas, em contrapartida as situações de trabalho modificam as percepções desse trabalhador de si mesmo, dos outros e do próprio trabalho.

Os músicos da banda consideram o horário de trabalho como um "tempo que sobra", que é utilizado para os ensaios à noite e fins de semana.

Os fatores de prazer são: gratificações, o reconhecimento e a liberdade no trabalho. Os fatores de sofrimento são: os desgastes (físicos e emocionais), insegurança profissional, falta de tempo para a família e sentimento de impotência na realização das tarefas.

A arte, o lazer e o trabalho são elementos vinculados que nem sempre estão em harmonia, seja financeiramente, socialmente ou afetivamente.

É comum as estratégias de enfrentamento utilizadas para evitar o sofrimento e a loucura. A reação dos músicos em situações difíceis é manifestada de forma individual e coletiva. São mecanismos de defesas que permitem que o estado de saúde mental do trabalhador não seja prejudicado, que ele não enlouqueça. São comportamentos e reações agressivas para lidar com o sofrimento e a pressão no trabalho; racionalização das atividades (exteriorizar o sentimento de frustração é outra forma de manifestação).

O sentido do trabalho para estes profissionais é mais artístico e cultural do que comercial.

Há falta de formação profissional adequada para os integrantes, exceto um assistente técnico.
Há supervalorização nas relações de trabalho, respeito mútuo, consideração e cumplicidade.

Como se pode perceber, a organização apresenta ritos e normas. Nota-se as vivência de prazer e sofrimento nas categorias da psicodinâmica conforme o objetivo da pesquisa.

O objetivo principal da psicodinâmica configura-se na tentativa de transformar o sofrimento em prazer por meio do trabalho, e esta abordagem enfatiza que o homem é um ser biopsicossocial.

Embasada na literatura da psicodinâmica, as vivências de prazer e sofrimento foram identificadas em todos os aspectos do trabalho: as condições de trabalho, as relações de trabalho, a organização do trabalho e as estratégias de enfrentamento.

Os resultados nesta pesquisa confirmam dados encontrados em outros trabalhos relacionados à arte, trabalho, lazer, prazer e sofrimento nas organizações, dentre eles os de Dejours (1992, 1994, 2004), Mascarenhas (2005), Polato (2004) entre outros já mencionados.

Esta pesquisa pode contribuir para a ampliação do trabalho científico e para a elaboração de proposta de melhoria às organizações que proporcionam lazer para as pessoas.

Para continuidade deste trabalho, sugere-se que pesquisadores interessados nessa linha tratem as seguintes questões em pesquisas futuras: (a) estudos comparando os estilos de trabalho de lazer: cultural ou comercial?; (b) arte: lazer pago ou lazer gratuito?

Viver exclusivamente da arte no Brasil ainda é uma raridade, o preconceito social no capitalismo vigente (onde o trabalho formal é supervalorizado), dificulta o reconhecimento e a identidade dos trabalhadores que proporcionam lazer para a sociedade.

\section{Referências}

Alves, G. (2006). Trabalho, subjetividade e lazer: Estranhamento, fetichismo e reificação no capitalismo global. In V. Padilha (Ed.), Dialética do lazer (pp. 19-49). São Paulo, SP: Cortez.

Amaral, S. C. F. (2006). Políticas públicas de lazer: Existe possibilidade de uma gestão participativa? In V. Padilha (Ed.), Dialética do lazer. São Paulo, SP: Cortez.

Araújo, S. (1998). Música e identidade social: A questão do folclore. Pesquisa em Música, 3.

Bendassolli, P. (2003-2004). Chega de diversão! GV-Executivo, 2(4), 57-61.

Brant, L. C., \& Minayo-Gomez, C. (2004). A transformação do sofrimento em adoecimento: Do nascimento da clínica à psicodinâmica do trabalho. Ciência e Saúde Coletiva, 9(1), 213223.

Cabral, A. C. (1999). A análise do discurso como estratégia de pesquisa no campo da Administração: Um olhar inicial. In Anais do XXIII Encontro Nacional da Associação Nacional de PósGraduação em Pesquisa em Administração [CD-ROM]. Foz do Iguaçu, PR: Enanpad. 
Codo, W., Menezes, I. V., Tavares, M., Lima, M. E. A., \& Diniz, G. (2004). O trabaho enlouquece? Um encontro entre a clínica e o trabalho. Petropolis, RJ: Vozes.

Dejours, C. (1992). A loucura do trabalho. São Paulo, SP: Cortez. Dejours, C. (1994). Psicodinâmica do trabalho. São Paulo, SP: Atlas.

Dejours, C. (1999). A banalização da injustiça social. Rio de Janeiro, RJ: Editora da Fundação Getúlio Vargas, 1999.

Dejours, C. (2004). Da psicopatologia à psicodinâmica do trabatho. Brasília, DF: Editora da Fundação Oswaldo Cruz.

Dimatos, A. M. M. (1999). O prazer no trabalho. Dissertação de Mestrado não-publicada, Universidade Federal de Santa Catarina, Florianópolis, SC.

Enriquez, E. (2001). O papel do sujeito humano na dinâmica do social. In M. N. M. Machado, E. Castro, J. Araújo \& S. Roedel (Eds.), Psicossociologia, análise social e intervenção (pp. 2743). Belo Horizonte, MG: Autêntica.

Enriquez, E. (2006, jan.-jun.). O homem do século XXI: Sujeito autônomo ou indivíduo descartável. RAE Eletrônica, 5(1), Artigo 10. Retirado de http://www.scielo.br/pdf/raeel/v5n1/ 29568.pdf

Fabiano, L. H. (2003). Adorno, arte e educação: Negócio da arte como negação. Educação e Sociedade, Campinas, 24(83).

Ferreira, M. C., \& Barros, P. C. R. (2003). (In) Compatibilidade trabalho prescrito - Trabalho real e vivências de prazer- Sofrimento dos trabalhadores: Um diálogo entre a ergonomia da atividade e a psicodinâmica do trabalho. Revista Alethéia, Universidade Luterana do Brasil, Canoas, RS.

Ferreira M. C., \& Mendes A. M. (2001). Só de pensar em vir trabalhar, já fico de mau humor. Atividade de atendimento ao público e prazer-sofrimento no trabalho. Revista Estudos em Psicologia, Natal, 69(1), 97-108.

Ferreira M. C., \& Mendes A. M. (2003). Trabalhos e riscos de adoecimento: $O$ caso dos auditores-fiscais da previdência social brasileira. Brasília, DF: Fenafisp.

Freitas, V. (2005). Indústria cultural: O empobrecimento narcísico da subjetividade. Revista Kriterion, 46(112).

Graciolli, L. S. (2006). Análise quali-quantitativa do uso de protetores auditivos especiais em músicos. Tese de Doutorado nãopublicada, Universidade Federal de Santa Catarina, Florianópolis, SC.

Heloani, J. R., \& Capitao, C. G. (2003). Saúde mental e psicologia do trabalho. São Paulo em Perspectiva, 17(2).

Johanson, I. (2004). Bergson e a busca metódica do tempo perdido. Trans/Form/Ação, 27(2).

Lacaz, F. A. C. (2000). Qualidade de vida no trabalho e saúde/ doença. Ciência e Saúde Coletiva, 5(1), 151-161.

Lancman, S., \& Heloani, R. (2004). Psicodinâmica no trabalho: O método clínico de intervenção e investigação no trabalho. Revista Produção, São Paulo, 14(3), 77-86.

Lane, S. (1985). A linguagem e a constituição do sujeito. Trabalho apresentado no XX Congresso Interamericano de Psicologia, Caracas, Venezuela.

Macêdo, A. B. F. (2003). Coração Nativo: Uma experiência musical com o mundo sonoro indígena. Tese de Doutorado nãopublicada, Universidade Federal de Goiás, Goiânia, GO.

Macêdo, K. B. (2001). Empresa familiar brasileira: Poder, cultura e decisão. Goiânia, GO: Terra.

Maheirie, K. (2001). Sete mares numa ilha: A mediação do trabalho acústico na construção da identidade coletiva. Tese de Doutorado não-publicada, Pontifícia Universidade Católica de São Paulo, SP.
Maheirie, K. (2003). Processo de criação no fazer musical: Uma objetivação da subjetividade, a partir dos trabalhos de Sartre e Vigotsky. Psicologia em Estudo, 8(2), 147-153.

Mascarenhas, F. (2005). Entre o ócio e o negócio: Teses acerca da anatomia do lazer. Campinas, SP.

Mascarenhas, F. (2006). Em busca do ócio perdido: Idealismo, panacéia e predição histórica à sombra do lazer. In V. Padilha (Ed.), Dialética do lazer (pp. 53-74). São Paulo, SP: Cortez.

Mendes, AM. (2002). Algumas contribuições teóricas do referencial psicanalítico para as pesquisas sobre organizações [Edição especial]. Revista Estudos em Psicologia, 7, 89-96.

Padilha V. (2006). Consumo e lazer reificado no universo onírico do shopping center. In V. Padilha (Ed.), Dialética do lazer (pp. 126-155). São Paulo, SP: Cortez.

Pagés, M. (1982). A vida afetiva dos grupos. Petrópolis, RJ: Vozes.

Pagés, M. (1987). O poder das organizações. São Paulo, SP: Atlas.

Pellegrin, A. (2006). Lazer, corpo e sociedade: Articulações críticas e resistências políticas. In V. Padilha (Ed.), Dialética do lazer. São Paulo, SP: Cortez.

Polato, T. H. P. (2004). Por um lazer potencialmente transformador: Um estudo sobre as apropriações conceituais do lazer. Tese de Livre-docência não-publicada, Universidade de Campinas, SP.

Tamayo, A., Faria, J. B., \& B. Filho, A. (1998). Diferenças nas prioridades axiológicas de músicos e advogados. Psicologia Reflexão e Crítica, 11(2), 281-294.

Daniela Tavares Ferreira de Assis é Psicóloga organizacional, Especialista em Gestão de Pessoas, Exprofessora convidada da Universidade de Rio Verde e Mestre em Psicologia Social do Trabalho pela

Universidade Católica de Goiás. Endereço para correspondência: Rua 4, 24, Apto. 900, Setor Oeste, Goiânia, GO, 74 110-024. Fax: (62) 3281-4800 daniela.assis@cultura.com.br

Kátia B. Macedo é Psicóloga, Psicanalista, Professora do Programa de Pós- Graduação da Universidade Católica de Goiás.

Psicodinâmica do Trabalho dos Músicos de uma Banda de Blues

Daniela Tavares Ferreira de Assis e Kátia B. Macedo

Recebido: 20/06/2007

$1^{\text {a }}$ revisão: $23 / 10 / 2007$

Aceite final: 9/11/2007 